\title{
RELATIONSHIP BETWEEN LATE BREAST MILK JAUNDICE AND HUMAN MILK CYTOKINE LEVELS
}

\author{
B. Ermis ${ }^{1}$, K. Apaydin ${ }^{2}$, M. Arasli ${ }^{3}$ I. Tekin ${ }^{3}$ \\ ${ }^{1}$ Pediatrics, University Sakarya, Sakarya, ${ }^{2}$ Pediatrics, ${ }^{3}$ Immunology, Karaelmas University, Zonguldak, \\ Turkey
}

Late onset breast milk jaundice (BMJ) is the most common cause of prolonged jaundice after 15th days of life. The diagnosis is confirmed by exclusion of other causes such as hypothyroidism, urinary tract infections and pylori stenosis. However, in most cases the cause can not be determined.

IL-1 beta levels in colostrum of mothers with early neonatal jaundice were reported to be higher than in the control group.

The aim of this study was to investigate whether there is a relationship between cytokine levels in the mature milk of nursing mothers and late onset breast milk jaundice.

Breast milk cytokine levels were investigated in infants with breast milk jaundice $(n=40)$, and results were compared to healthy controls without jaundice $(n=40)$.

IL-1 beta levels were found to be significantly higher in the study group compared with the control group (p $=0.013)$. There was no significant difference between IL-6 $(p=0,174), \operatorname{IL}-8(p=0,285), \operatorname{IL}-10(p=0,067)$ and TNF-alpha $(\mathrm{p}=0,053)$ levels.

As a result, it is seen that the concentration of IL-1 beta is also associated with late breast milk jaundice. The late breast milk jaundice is likely possible to be a continuation of early breast milk jaundice. 